\title{
Can the Use of Clickers or Continuous Assessment Motivate Critical Thinking? A Case Study Based on Corporate Finance Students
}

\author{
Lucía Morales a, b, * \\ a Dublin Institute of Technology, Ireland \\ b University of Liverpool Online, UK
}

\begin{abstract}
This study explores the use of clickers as a tool to support, encourage and motivate critical thinking in higher education students. A case study was carried out with a cohort of undergraduate students undertaking the BSc. in Accounting and Finance during the academic year 2009/10, were corporate finance was a major component. Since the students in this sample had previously demonstrated passivity during their corporate finance classes, it was proposed that clickers would help motivate them to participate during face to face sessions. Previous research on the use of clickers shows evidence that this tool has a positive effect on student participation and interaction in the classroom. The results of this study suggest that clickers can positively affect classroom dynamics; they help activate the learning experience and provide a more relaxed atmosphere, where students can interact with their teacher. However, little evidence was found to indicate that clickers are a good device to enhance critical thinking skills. In this context, strategies based on a problem-centered approach to learning appear to provide a better outcome.
\end{abstract}

Keywords: classroom dynamics, critical thinking, motivation, clickers, audience response, continuous assessment, corporate finance

\section{Background}

Audience response systems (ARS) or "clickers" are currently being used in a variety of fields and at all levels of education (Caldwell, 2007). Previous studies have found that clickers can either have a benign or positive effect on student performance, and minimal effects on exams results (Caldwell, 2007; Martyn, 2007; Morgan, 2008). According to Caldwell (2007), depending on the method and extent of their use, clickers can create a more positive and active classroom atmosphere, and can make the overall learning process more enjoyable. ARS are particularly useful as a means to introduce and monitor peer learning methods in the large classrooms. Indeed, students and teachers who have used this tool are generally positive and enthusiastic about its effects. Moreover, educators and researchers emphasise the great potential of ARS for improving student learning (Beatty, Gerace, Leonar, \& Dufresne, 2006).

Previous studies indicate that, in general, clickers tend to be appreciated as a tool that can contribute to students' motivation and engagement during lectures. Following a review of the literature, the current study was designed to integrate this technology into final year corporate finance classes of a BSc. in Accounting and Finance. To do so we analyse how these students respond to the use of clickers in their lectures and examine whether this tool offers support in motivating and engaging students in peer discussions during lectures.

*Corresponding author (lucia.morales@dit.ie | lucia.morales@my.ohecampus.com)

Suggested citation: Morales, L. (2011). Can the use of clickers or continuous assessment motivate critical thinking? A case study based on corporate finance students. Higher Learning Research Communications, 1(1), 33-42. http://dx.doi.org/10.18870/hlrc.v1i1.31 
The choice of using this sample was based on the authors' experience of teaching undergraduate and postgraduate students over a two-year period (September, 2008-May, 2010) where finance is an important element of the course. Overall, during this period the author observed that students tend to follow a similar pattern of behaviour towards the subject matter and the teaching; this can be best characterised as "passive" learning. Anecdotal observations were summarised as follows:

a) Students are generally passive, as demonstrated by their lack of interaction with the teacher even when direct questions on a particular issue are asked.

b) It is difficult to motivate and engage the students in any classroom discussion. Group discussions were introduced to support and encourage interaction, yet this strategy has not produced significant results, and the students' attitudes remain unchanged.

c) Students are reluctant to participate during class, even when it is clear that they have covered the material during previous years on the programme; this may be due to a lack of confidence.

d) Due to the lack of interaction it is difficult to detect whether the students are following the material under discussion. As a result, it is difficult for the teacher to know which areas of the course should be focused on.

e) It is necessary to asses and improve students' critical thinking skills in this subject through the use of continuous assessments, case studies, and group projects.

Based on these observations, it was necessary to take measures to improve the classroom dynamics. A teacher must ensure that students undertaking finance programmes acquire the skills to critically analyse problems, and moreover have the ability to apply these skills to real life situations. For this reason, ARS were introduced to support lectures. This makes it possible to identify whether clickers can motivate students to participate during classes and enhance students' critical thinking skills. This strategy was combined with a problem centred approach to learning.

The present paper is divided into seven sections. In section two, clickers are defined and introduced into the context of this study. Section three and four comprise a review of the literature concerning the concept of critical thinking in relation to finance and the rationale for using clickers to enhance students' participation in the classroom. In section five a case study is presented and in section six, the findings are reported. Finally, section seven gives conclusive remarks, where limitations of this study and recommendations for further research are outlined.

\section{Clickers Context and Definition}

Before discussing the literature analysing the effects of clickers on student learning, it is important to provide a brief definition of what clickers are and consider their main contribution to the learning process. Clickers are handheld devices used as Audience Response Systems (ARS) and are commonly known as "key pads" in the United States or "handsets" or "zappers" in the United Kingdom (d'Inverno, Davis, \& White, 2003; Simpson \& Oliver, 2006). These small transmitters are used by students to electronically transmit their answers by pressing the clickers' buttons. They can be used in many ways in an educational context. For example, see studies by Caldwell (2007), Simpson and Oliver (2006), d'Inverno et al., (2003):

- to increase and manage student interaction in the classroom;

- to assess students' understanding of a subject and misunderstanding of any content in a lecture;

- to guide thinking and review the learning materials; 
- to conduct experiments and motivate student learning.

Clickers are considered to be a flexible tool, limited only by the imagination of the teacher, his/her questioning format, and the way they are presented to students. Many teachers have adopted clicker technology to enliven their teaching and to minimise poor concentration and interaction, which is characteristic of the traditional lecturing environment. In courses where clickers have been used, the classroom dynamic has changed to the extent that the typical lecture structure is abandoned altogether or reduced substantially (Draper and Brown, 2002; Cutts Kennedy, Mitchell, \& Draper, 2004; Knight \& Wood, 2005). These "interactive engagement" or "peer instruction" methods are very effective, but still quite new to most teachers. Many creative strategies to prompt student participation have been utilised, from asking on student volunteers to interact, calling student names. However, these methods prove to encourage participation from only a fraction of the class. In this regard, clickers are considered beneficial in facilitating the learning process as they can be used in a way that supports student-teacher engagement through frequent assessment (Roschelle, Penuel, \& Abrahamson, 2004). They also offer rapid feedback to the teacher concerning both the course content and the quality of teaching (Draper and Brown, 2002). In general, students believe that clickers are fun, and that their use stimulates the atmosphere in the classroom. Teachers who use this tool report less lethargy in students, more discussion and improved alertness during class (Jackson \& Trees, 2003).

As outlined above, the class cohort used in this study is characterised by a high level of passivity and a lack of interaction during lectures. It is quite difficult to encourage the students to be involved in the classes and almost impossible to get them to respond to direct questions. In terms of any potential downside to the use of clickers in the classroom, it is important to note that clickers can have a negative effect in the classroom. Some students are more comfortable in a traditional learning environment and feel inconvenienced by technology in the classroom. Another potential drawback to the use of clickers is the teacher's lack of familiarity with the techniques and procedures required to use this tool optimally. This can have a negative effect on learning outcomes, as the focus tends to be on the technology being used, rather than on the course content.

\section{Critical Thinking in Finance}

Over the last few decades, critical thinking has been defined in a number of different ways. Below we present a few definitions, particularly within the context of finance. Norris (1985) posits that critical thinking is deciding rationally what to believe or what not to believe. Elder and Paul (1994) suggest that critical thinking is best understood as the ability of thinkers to take charge of their own thinking. Harris and Hodges (1995) define critical evaluation as the process of arriving at a judgment about the value or impact of a text by examining its quality. More recently, Duron, Limbach, and Waugh (2006) define critical thinking as the ability to analyse and evaluate information. Duron et al. (2006) conclude that "critical thinkers are considered to be able to raise vital questions and problems, formulate them clearly and gather and assess relevant information, use abstract ideas, think open-mindedly, and communicate effectively with others" (p. 160). In this context, and considering the current economic and financial climate, it is important that critical thinking skills are a central part of finance courses, as these skills represent a valuable asset in the work place. It is arguable that using the traditional lecture format in finance degrees may not adequately foster active learning or critical thinking skills in finance students, as it is based on a teacher-centred approach. As a result, it is important to adjust the structure of lectures to promote such skills. Not only would this make the course work more enjoyable for both students and teachers, it will equip students with the skills necessary in their future careers. During a lecture, 
the teacher must consider the kinds of active learning that can encourage critical thinking. To enhance the overall learning experience, it is necessary have a broad understanding of what active learning constitutes. Strategies may include requesting students to participate by, for example, giving information and ideas, sharing experiences, and offering opinions. This study investigates how the use of clickers affects the learning experience of a cohort of finance students during one semester of their course. More specifically, we analyse whether student interaction, critical thinking skills, and exam scores improve with the use of clicker technology.

\section{Rationale for Audience Response Systems}

In what follows, previous studies exploring the impact of Audience Response Systems (ARS) or "clickers" in higher education are discussed. In order to ascertain how students and lecturers have reacted to the implementation of new techniques in their traditional teaching schedules, we first examine the research findings based on lectures supported by technology. Regarding clickers as motivators of lifelong learning in higher education, research has produced mixed conclusions. There is disagreement concerning the real benefits of introducing this technology into the classroom to support learning. Thus, the question as to whether or not clickers generate clear benefits to student learning must be explored.

Some studies suggest that clickers enhance student outcomes, such as exam scores, passing rates, student comprehension, and moreover, that students appear to like clickers (McDermott \& Redish, 1999; Roschelle et al., 2004; Duncan, 2005; Simpson \& Olivier, 2006). However, to date, much of the research conducted is not systematic enough to permit scientific conclusions about the benefits of ARS in the classroom (Roschelle, 2004, Simpson \& Olivier, 2006). Educational researchers argue that covering course content alone is not the most effective way to teach students and that active engagement leads to more effective learning (Draper, Cargill, \& Cutts, 2002; Cutts et al., 2004; Knight \& Wood, 2005; Simpson \& Olivier, 2006). In this respect, peer learning appears to work; students who use class time primarily to discuss assigned topics in small groups do at least as well or better than students who undergo traditional lectures. Taking this into consideration, it's possible that clickers can offer powerful and flexible support for teaching, as they can be used in a variety of subjects with students of almost any level of academic training. To offer a balanced perspective, below we present studies that support the use of clickers and research that shows that the use of clickers does not generate a major impact in the classroom.

\section{The Positive Impact of Clickers in the Classroom}

Research on classroom response systems indicates that when used with active learning techniques such as peer instruction (PI), clickers can improve student learning in measurable ways. The use of clickers with Peer Instruction is an interesting line of research. In this context, Crouch and Mazur (2001) analysed ten years of introductory physics courses for non-majors at Harvard University, which used Peer Instruction as a teaching method. This technique modifies the traditional lecture format to include questions designed to engage students and uncover difficulties they may have with the material. The authors found that students develop and retain a better understanding of the learning material after classroom discussions. Moreover, after implementing PI the authors found that students' results improved dramatically, and students' motivation and reaction to PI were generally positive.

Furthermore, Draper and Brown (2004) provide an overview of their experience of introducing an electronic voting system (clickers) for use in lectures. The authors conclude that such Information and Communication Technology (ICT) must be used to support the teaching 
pedagogy, not as the main reason for teaching. The most important features of using clickers as reported by students were: i) getting feedback from teachers about whether they understand the material presented (i.e., that it prompts most students to think about the question and decide on an answer, while alternative approaches do not); and ii) its anonymity, which is important in achieving such feedback. Thus, the benefit of using clickers does not depend simply on the use of this technology to support classes: the most important feature is how well this device is used to promote learning interactivity and reflection in learners.

In terms of lecturing, Duncan (2005) argued that no matter how good a teacher you are, if you teach solely by lecture you will lose the attention of your students just minutes after your class has begun. This "fade in" attention span is a universal phenomenon, but could be tackled by using interactive systems such as clickers and thus maintain a much higher level of student involvement.

Looking at classroom dynamics and lecturing strategies, Draper and Brown (2004) discuss contingent and agile teaching, whereby the instructor is able to identify whether students are following their lessons. Depending on the answers given by the students, the teachers can alter the classroom activities, for example by introducing peer discussions or group assignments. In this context, clickers can promote active participation, engagement and discussion among all students, even those who might not typically participate in class discussions.

Similarly, Bruff (2007) analyses the use of clickers as a classroom innovation, having the great advantage of allowing teachers to assess student learning in real-time, during class. Clickers can be used in different ways in classroom activities, and can successfully change classroom dynamics. As students' attention can fade only a few minutes after a session starts, clickers can be used to break the traditional lecturing format, where most of the attention is focused on the teacher rather than on the student. In this way, the class routine will benefit from a change, where students will be the centre of attention as they are the ones to interact with the class in an innovative and practical way. In sum, not only can this tool be used to motivate peer collaboration through discussion, it also facilitates individual learning and instant feedback.

Keller et al. (2007) demonstrates that students' perception of the utility of clickers improves as teachers encourage peer-discussion and succeed in getting students to discuss issues with each other during a lecture. Students' attitudes are also strongly affected by the extent to which teachers encourage and succeed in generating peer-discussion during the administration of clicker questions. In line with the findings of Menz, Jungic, and Wiebe (2009), clicker activities appear to lend themselves to alternative modes of delivering lectures, which is greatly appreciated by students. However, designing appropriate questions, creating slides, and preparing the lecture material can be a time consuming job. Nevertheless, they should be taken seriously if clicker activities are to be worthwhile.

\section{Challenges of Using Clickers in the Classroom}

The challenges to the use of clickers have been documented by Johnson and Robson (2008), who examined whether clickers affected learning in an introductory economics course. The authors found no significant differences between the clicker and non-clicker sessions in students' attendance, participation or class engagement. Moreover, no difference was found in exam performance. The authors conclude that teachers should be cautious when "patching" new technologies into traditional lecture courses, and that universities should be cautious about making the use of technology mandatory. 
Martyn (2007) outlines the benefits of active learning approaches, clickers or Student Response Systems (SRS). The author found that clickers provide a mechanism for students to participate anonymously, and advocates the "game approach," over traditional class discussion, for engaging students in class activities. The anonymity of responding with a clicker can guarantee almost total participation. This is very important; Johnson (2004) believes that many students are reluctant to respond to a question until they know how others will respond. Moreover, students were reported to perceive value in the use of clickers and recommend their use in classes. However, learning outcomes of students using clickers did not improve more than a traditional active learning approach, such as class discussion (Johnson, 2004).

Morgan (2008) explored the negative impact of clickers and revealed that, contrary to expectation, attrition levels were higher and grades lower in courses that used clickers. Although the differences were not statistically significant, Morgan's (2008) study shows that lecturers and students did not respond positively to clickers. Willoughby and Gustafson (2008) suggest that many instructors use clicker questions to stimulate classroom discussion and to spark students' interest. However, this study concluded that student behaviour may be altered when they are in the presence of digital recorders in the classroom, prompting more activity and paying more attention to their classes.

A review of the literature reveals that systematic evidence of the practical effectiveness of clickers in the classroom is lacking. While clickers do seem to enhance students' active learning, participation, and enjoyment in class, there is no clear evidence to conclude that clickers actually improve student learning outcomes. Research indicates that when clickers are used during lectures, they have either a neutral or a positive effect on learning outcomes, which improves when clickers are combined with peer or cooperative learning. In recent years, numerous teachers have started to use student response systems to enhance the teaching and learning in their classroom. It appears that while clear evidence for the benefits of using clickers is lacking, teachers who have used this tool in the past to support their classes, are continuing to opt for this technology (Woelk, 2008). Thus, in spite of mixed opinions in the literature, there is a general agreement that clickers are perceived as a tool that can help change the classroom dynamics, and it is up to the teacher to determine how it will be used in the classroom.

\section{Research Design}

\section{Case Study}

Qualitative case studies provide researchers with the tools to explore complex phenomena, and can be used to improve our understanding of how teachers can develop and implement teaching techniques that enhance students' learning experience. Case study research is more than simply conducting research on a single individual or situation: a case study has the potential to incorporate aspects of both simple and complex situations. It enables the researcher to answer "how" and "why" type questions, while taking into consideration how a phenomenon is influenced by the context within which it is situated (Baxter \& Jackson, 2008).

The present case study is based on a group of fourty six final year students (during semester two of the academic year 2009-10) undertaking a BSc. in Accounting and Finance at Dublin Institute of Technology (DIT). Clickers were introduced to lectures to explore whether this tool would help enhance students' contribution to class discussions and critical thinking skills. The sample used for the case study was chosen by the author for reasons of previous experience: the author taught corporate finance to final year students on this programme for two years (September, 2008 to May, 2010). During this time, it was observed that students' participation 
during classes was very low. Such a lack of interaction between the students and teacher is frustrating, as it does not allow the teacher to identify whether students are following the course material.

The authors' experience of teaching this module showed clear evidence that the students were struggling with the course material, and that their critical thinking skills were deficient when dealing with financial issues; this translated into poor results on their assignments. Consequently, the author introduced a problem centred learning approach supported by weekly assignments. For these continuous assessments the author designed theoretical and practical questions which were given to the students at the end of each week. Every student had to review the material that had been covered during classess. Once this review was completed, each student had to attempt to answer the questions presented in their weekly assignment. The emphasis of this assignment was on whether they had been able to apply the concepts learned during the week; through this process their critical thinking should be clear to asses. These assignments provided very good results and at the end of the year it was obvious that students' critical thinking skills had improved, as they achieved higher grades in their assignments and final exams.

Because the use of weekly assessments was successful during the first year of the programme (September, 2008- May, 2009), the same strategy was used to support lectures during the following academic year (September, 2009-May, 2010). It is important to note that the students' initial response to the weekly assessments was one of complete rejection. During the first semester of the course, students complained about this approach; the major points highlighted by the group were as follows:

1. They considered the weekly assignments to be an excessive amount of work.

2. They wanted fewer questions in the assignments, and more time to complete their answers.

3. They did not know what critical thinking was and what the expectations of the assignments were; this translated into continuous complaints from the students, and frustration on behalf of the teacher.

4. They compared the amount of work that they had to do in these modules with other modules, and complained that they had less work in other modules.

5. A minority wanted the weekly assignments to be completely eliminated from the module's assessment strategy.

Taking into account the students' complaints, in the second semester of academic year 2009/10 clickers were used in addition to the weekly assignments in order to ascertain whether this tool would provide a better outcome when used with the fourty six students. More specifically, there was an examination to determine if there was an improvement in students' critical thinking skills and participation during the classes.

\section{Research Findings}

The results of this study suggest that clickers are an effective tool for changing classroom dynamics and provide an alternative to the traditional learning approach, where students' assumed a very passive attitude. Overall the use of clickers helped provide an environment where students were more relaxed and less apprehensive. However, clickers where not found to be very helpful in the following situations: 
1. In terms of improving or motivating students' critical thinking skills, the results were not very encouraging. This problem remains and students were reluctant to participate when a question was posed after obtaining the responses from the poll.

2. It was difficult for the teacher to detect whether students were sincere when providing their answers, as it was possible that they were guessing and not responding based on their knowledge. In this way the efficacy of clickers is limited, as the issue regarding students' real understanding of the material being covered remains uncertain. The problem centred approach seemed to be a better way of assessment. The use of case studies, tests, questions that allow students to provide short and long answers during tutorials helped them consolidate their knowledge.

3. Therefore, there was little or no improvement in the students' performance after using clickers, in comparison to classes that were taught without the support of this tool: when using clickers, students were still not willing to participate and interact during classes and performed better when submitting their weekly assignments. In terms of the weekly assignments, the progress was very clear; during the first semester students struggled a bit and their work was not of high quality. This pattern changed when the teacher provided general feedback to the class, identifying their weak points and where they should make an effort to improve their work. At the end of the first semester, students were submitting better quality work and, in general, all students were reaching higher standards in the subject. This type of assessment provided direct information in terms of topics that were well understood by the class, and which ones which were more complex and needed further explanation. In this way, clickers were not helpful, as it was not possible to identify through short questions if students were achieving an understanding of the topics under analysis.

4. Finally, when using clickers, students did not seek clarification, or ask for further explanations; they limited themselves to pressing a button and waiting for the next question. This interaction was very frustrating for the teacher and did not provide the expected result. It was very difficult to get students to interact during class or to motivate them. In spite of the great effort and considerable time put into designing questions to suit the use of clickers no clear impact on students' performance was observed.

These findings are in line with previous research suggesting that clickers do not generate an improvement in students' understanding of the teaching material or enhance critical thinking skills (Johnson \& Robson, 2008. Nevertheless, when students were asked if they would like their classes to be supported with this type of technology their answer was positive in general. However, as shown by Martyn's (2007) active learning approach, class discussions during normal tutorials using a problem centred approach were found to be better. In line with Morgan (2008), the present study did not find evidence of an improvement in class attendance or engagement in classroom activities. Moreover, in this study it was observed that the use of clickers requires an extra amount of work that did not prove to be worthwhile. As mentioned above, more satisfactory results were obtained by using a problem centred approach rather than introducing a new tool to support the classes. Time and planning must be dedicated to the design of efficient assessment materials to better support students. While there may be a place for clickers in the classroom, special attention must be paid to how this tool should be best integrated into teaching.

\section{Conclusions and Further Research}

The present study explored the effect of clickers on promoting and developing critical thinking in students and encouraging participation during lectures. The case study comprised 
final year students at the Dublin Institute of Technology undertaking an undergraduate degree where finance is a major component.

The results of this study support previous research suggesting that clickers can help to create a more positive and active atmosphere in large classrooms, as they can make the learning process more enjoyable for students. According to Martyn (2007), students do perceive some value in the use of clickers, as they are able to work in a more relaxed atmosphere. Consequently, students recommend their use in classes to enhance teaching and learning strategies. However, in this study the use of clickers did not prove to be an efficient tool to help improve students' participation rate in class or help develop critical thinking skills. In this context, a problem centred learning approach was seen to be more appropriate and effective.

In the case study reported, the teacher's experience and interaction with the class showed that some students did not want to participate; on many occasions the poll closed with an 80$90 \%$ participation rate. While this rate may not be generalisable to every classroom, it seems that $10-20 \%$ of students are not comfortable using this tool during their classes. Therefore, the present study provides some evidence that clickers can potentially change the dynamics in the learning environment and support active learning in the classroom. However, it is still unclear as to whether they are an effective means of encouraging and promoting participation and critical thinking skills in students. Further research is necessary to assess the potential of clickers to improve and develop critical thinking skills in students. Future research should explore strategies of integrating this tool into the classroom in a way that is effective an efficient, rather than using it solely to help relax the classroom atmosphere.

\section{Study Limitations}

A limitation of this study concerns use of two methods of supporting academic performance with the same sample of students and the lack of a control group. Clickers were introduced during the second semester of the academic year 2009/10, when students were already receiving feedback and instruction in relation to the continuous assessment. This meant that a learning process had already taken place, and it was not possible to ascertain the extent of the effect that clickers had on students' performance. Moreover, the teacher's inexperience in using this tool may have also impeded its full potential.

\section{References}

Baxter, P., \& Jackson, S. (2008). Qualitative case study methodology: Study design and implementation for novice researchers. The Qualitative Report, 13(4), 544-559.

Beatty, I. D., Gerace, W. J., Leonar, W. J., \& Dufresne, R. J. (2006). Designing effective questions for classroom response system teaching. American Journal of Physics, 74(1), 31-39. http://dx.doi.org/10.1119/1.2121753

Bruff, D. (2007). Clickers: A classroom innovation. National Education Association, 25(1), 5-8.

Caldwell, J. E. (2007). Clickers in the large classroom: Current research and best-practice tips. CBE-Life Sciences Education, 6(1), 9-20. http://dx.doi.org/10.1187/cbe.06-12-0205

Crouch, C. H., \& Mazur, E. (2001). Peer instruction: Ten years of experience and results. American Journal of Physics, 69(9), 970-977. http://dx.doi.org/10.1119/1.1374249

Cutts, Q., Kennedy, G., Mitchell, C., \& Draper, S. (2004, August). Maximizing dialogue in lectures using group response systems. Paper presented at the 7th IASTED International Conference on Computer and Advanced Technology in Education, Hawaii.

d'Inverno, R., Davis, H., \& White, S. (2003). Using a personal response system for promoting student interaction. Teaching Mathematics and Its Applications, 22(4), 163-169. http://dx.doi.org/10.1093/teamat/22.4.163 
Draper, S., Cargill, J., \& Cutts, Q. (2002). Electronically enhanced classroom interaction. Australian Journal of Education Technology, 18(1), 13-23.

Draper, S. W., \& Brown, M. I. (2004). Increasing interactivity in lectures using an electronic voting system. Journal of Computer Assisted Learning, 20(2), 81-94. http://dx.doi.org/10.1111/j.1365-2729.2004.00074.x

Duncan, D. (2005). Clickers in the classroom: How to enhance science teaching using classroom response systems. San Francisco, CA: Pearson Education.

Duron, R., Limbach, B., \& Waugh, W. (2006). Critical thinking framework for any discipline. International Journal of Teaching and Learning in Higher Education, 17(2), 160-166.

Elder, L., \& Paul, R. (1994). Critical thinking: Why we must transform our teaching. Journal of Developmental Education, 18(1), 34-35.

Harris, T., \& Hodges, R. (Eds.). (1995). The Literacy Dictionary: The vocabulary of reading and writing. Newark, DE: International Reading Association.

Jackson, M. H., \& Trees, A. R. (2003). Clicker implementation and assessment [Report]. Department of Communication, University of Colorado at Boulder.

Johnson, M., \& Robson, D. (2008). Clickers, student engagement and performance in an introductory economics course: A cautionary tale. CHEER Virtual Edition, 20, 4-12.

Keller, C., Finkelstein, N., Perkins, K., Pollock, S., Turpen, C., \& Dubson, M. (2007, August). Research-based practices for effective clicker use. Paper presented at the Physics Education Research Conference, Greensboro, NC. http://dx.doi.org/10.1063/1.2820913

Knight, J. K., \& Wood, W. B. (2005). Teaching more by lecturing less. Cell Biology Education, 4, $298-310$. http://dx.doi.org/10.1187/05-06-0082

McDermott, L. C., \& Redish, E. F. (1999). Resource letter PER-1 on physics education resource. American Journal of Physics, 67(9), 755-767. http://dx.doi.org/10.1119/1.19122

Martyn, M. (2007). Clickers in the classroom: An active learning approach. EDUCASE Quarterly, 2, 71-74.

Menz, P., Jungic, V., \& Wiebe, A. (2009). Instructors and student feedback on clickers in large calculus courses. Department of Mathematics, Simon Fraser University. Retrieved from http://www.sfu.ca/math.html

Morgan, R. P. (2008). Exploring the pedagogical effectiveness of clickers. InSight: A Journal of Scholarly Teaching, 3, 31-36.

Norris, S. P. (1985). Synthesis of research on critical thinking. Educational Leadership, 42(8), 40-45.

Roschelle, J., Penuel, W. R., \& Abrahamson, L. (2004, April). Classroom response and communication systems: Research review and theory. Paper presented at the Annual Meeting of the American Educational Research Association, San Diego, CA.

Simpson, V., \& Oliver, M. (2006). Using electronic voting systems in lectures [UCL Internal report]. Retrieved from http://www.ucl.ac.uk

Willoughby, S. D., \& Gustafson, E. (2008). Technology talks: Clickers and grading incentive in the large lecture hall. American Journal of Physics, 77(2), 180-183. http://dx.doi.org/10.1119/1.3013542

Woelk, K. (2008). Optimizing the use of personal response devices (clickers) in large-enrollment introductory courses. Journal of Chemical Education, 85(10), 1400-1405. http://dx.doi.org/10.1021/ed085p1400 